\title{
The use of pesticides in French viticulture: a badly controlled technology transfer!
}

\author{
Alain Garrigou ${ }^{\text {a,b,*, }}$, Isabelle Baldi ${ }^{\mathrm{b}}$, and Marçal Jackson ${ }^{\mathrm{c}}$ \\ ${ }^{a}$ Department of Hygiene, Sécurité \& Environnement, Technical Institute of University Bordeaux 1, 15 rue Naudet, \\ 33175 Gradignan, France, \\ b Laboratoire Santé Travail Environnement, ISPED, Université Bordeaux 2 \\ ${ }^{c}$ Fundacentro, Rua Capote Valente, 710 - 05409-000 São Paulo SP.
}

\begin{abstract}
The use of pesticides is one of the techniques employed in modern agriculture and in particular in intensive agriculture. The risks for the environment and for worker health have been debated in western countries for about ten years. Recent developments in epidemiology, toxicology and ergotoxicology have clearly revealed that pesticides could harm the health of farmers (cancers, neurological diseases and reproductive disorders). Failures and shortcomings in the risk prevention systems have also come to light. This paper aims to address the risks associated to the use of pesticides in French vineyards. The chosen approach draws from an anthropological approach as well as from developments in ergotoxicology applied to the French vineyard work. We shall discuss the use of pesticides from the point of view of the transfer of technology. Our recent research has shown that this technology transfer was not completely controlled by the different stakeholders.
\end{abstract}

Keywords: pesticides, agriculture, anthropotechnology, ergotoxicology, technology transfer. 


\section{Introduction}

The anthropotechnology created by Wisner $\left[{ }^{1}\right]$ played a key role in the development of the problematics associated with the use of pesticides in agriculture, which then gave birth to ergotoxicology (Sznelwar $\left[{ }^{2}\right]$; Mohammed-Brahim, $[3]$; Garrigou et al., $\left.\left[{ }^{4}\right]\right)$. The starting point of anthropotechnology in terms of toxicology was the analysis of the working conditions of agricultural workers in tropical countries. From initial concerns that were mostly focused on the physiological and physical demands (heat, humidity, strenuousness...), Wisner tackled the question of worker exposure to pesticides. He built up on Silva's work (Silva et al., $\left[{ }^{5}\right]$ ) to set the stakes on worker health. "Next to a hedge, a young man was dipping cane stalks that were to be planted into a bucket filled with an orange liquid. The young man's clothes were soaked in the liquid, which turned out to be a common organomercurial insecticide. (...) An investigation revealed that there was a local epidemic of mercury paralyses, which had been diagnosed as poliomyelitis-related by practitioners who were not aware of occupational hazards". The use of pesticide can then be seen as a transfer of technology between different countries and different contexts. Veiga's work (Veiga et al., [ ${ }^{6}$ ] and $\left[{ }^{7}\right]$ ) shows that similar stories are still happening today, in particular in so-called developing countries such as Brazil. In today's context of increased global pressure on agricultural production (for food or biofuels, for example) it is also likely that such situations will multiply.

We shall also consider the questions of PPE design and use as a transfer of technology issue (Wisner [1]; Palis et al., $\left[^{8}\right]$ ). They were designed for work situations that have little in common with the working conditions in agriculture. The work environment and the environmental factors are much less predictable and controllable than in industrial setting (suits may get torn with vegetation, the sprayer tank can overflow, nozzles can get blocked, the weather can vary greatly and in turn greatly change the strenuousness...). In that respect, the efficiency of PPE can be discussed.

\section{Methodology}

In this paper we shall try to combine different data sources so as to show that the use of pesticides in France is the result of a badly controlled technology transfer. We will refer to a body of knowledge derived from a review of literature as well as from research which we led or to which we participated.

\section{A critical approach of risk prevention applied to the use of pesticides in France}

The general principles of prevention distinguish three layers of safety. The first concerns actions taken at the source, eliminating the hazard or replacing a dangerous process or product by one that is less dangerous. The second layer focuses on setting up collective or personal protective equipment, with the emphasis on collective protective measures, deemed more effective than personal protective equipment. The third layer consists in planning for first aid and rescue if an unwanted event occurs in respect to the risk in question.

If this reasoning is applied to the use of pesticides in France, the marketing authorisation has to be considered as one of the means of primary prevention. Protective and/or filtering booths and cabs (on tractors for example) can be seen as in-between collective and personal protection systems. Finally, protective suits and clothing are personal protective equipment. We shall discuss in the following part the effectiveness of the existing protection measures.

\subsection{The limitations of the pesticide marketing authorisation process}

The marketing authorisation is conditioned by regulations at European and French levels. The authorisation is granted by the French Department for Agriculture that relies on a risk/effectiveness analysis carried out by the French National Agency for the Health and Safety of Food, Environment and Work (ANSES).

This regulation is stricter than for other chemicals. Based on studies provided by pesticide manufacturers, assessors use models, essentially two English-language tools (UK POEM, ...) designed in the early 1990s. These models use an acceptable occupational exposure level (AOEL) for the operator, defined at European level. This reference value, determined by animal testing is the maximum quan- 
tity of active substance to which an operator can be exposed without harmful effects on their health. If the assessed exposure level for the substance (in the conditions of use of the product: dose, surface, equipment...) is below the AOEL, the risk is then considered as "acceptable". Exposure is measured with and without PPE, i.e. gloves and cotton / polyester suit, as the contamination mostly occurs by skin contact. In these models, the performance of protective clothing is estimated a priori at $90 \%$ or 95 $\%$ depending from the models.

The marketing authorisation must be seen as an organisational barrier aiming to assess the levels of risk that arise from the new molecules engineered by pesticide manufacturers as they make up an essential component in the pesticide risk prevention system.

However, the system and the models on which it relies present limitations and flaws that have a significant impact in terms of prevention. With this in mind, we can remark that there is a gap between the work situation modelled a priori in the assessment process and the real situations in which pesticides are used. This gap mostly concerns the modelling of the situations in which pesticides are used. The models do not correspond to the very diverse social, technical and cultural contexts in which pesticides are used in reality. In that sense, what is happening is a technology transfer whose limitations can be brought to light by anthropotechnology.

The marketing authorisation has limitations. The toxicological models on which it relies have been mostly designed for vast farms and crops, e.g. cereals, and need extrapolating for specific cultivations and tasks. The focus is on large agricultural enterprises and small farm realities are underestimated. Indeed large farms are most often equipped with more recent and effective tools and machines than smaller farms. What's more, in a large farm pesticide related tasks will generally be entrusted to a worker who has received specific training, especially in terms of mixing and dosing. In a small farm the work organisation, the technical resources as well as the prevention culture are likely to be very different, which implies most often that the risk will not be adequately controlled. In the case where the farm is spread on separate fields and surfaces, multiple mixing and dosing of small quantities of pesticides will be more frequent, and so will be transportation. Such conditions have consequences on contamination risks and are virtually absent from largdonfarnthose estimates of the risk level only concern the active substance. What is assessed is the mixture which contains the active substance of interest. However our previous research (Pestexpo, Baldi \& al. $\left.\left[{ }^{9}\right]\right)$ have shown that pesticides are actually mixtures that also contain additives, designed for some to facilitate the fixation on and penetration into the plant and that as such will also accelerate skin penetration. It can be frequently observed in the daily use of pesticides that winegrowers mix different commercially available pesticides (and then different active substances) so as to minimise the duration and transportation necessary for treatment. In this case, as for any other mixture of chemicals, interactions between pesticides and active substances deeply alter their toxicological properties, making the marketing authorisations useless.

\subsection{Limitations in the effectiveness of filtering cabs}

An analysis of the agricultural equipment design process shows that it consists more in the combination of existing equipments from different sectors rather than in a global design approach. The safety issues are only addressed minimally from existing machinery standards. The design process only marginally addresses the issues of utilisation and worker protection. When this is the case, the focus is mostly on mechanical hazards. Contamination of workers by pesticides is not taken into consideration in the design stages.

If we focus now on the effectiveness of tractor filtering cabs the impact of the above mentioned design issues becomes clear. In effect, cabs are not designed before production begins, at the same time as the rest of the tractor; they are adapted to fit a particular model of tractor. There are some flaws in the pairing of a cab and a tractor which compromise the airtightness of the cab. Those flaws are particularly associated to the pneumatic or electric control cables that go from the dash board in the cab to the different equipment they control. (see Figure 1).

An evaluation of the real effectiveness of new filtering systems shows that they can filter dusts but even the best systems are not effective against aerosols.

In a real work situation such performance is quickly compromised if the cabs are not completely airtight or if the filtering systems are not properly maintained. It must also be noted that the joints of windows tend to dry out, shrink and twist out of 
shape, which makes it possible for the pesticides to penetrate into the cab.

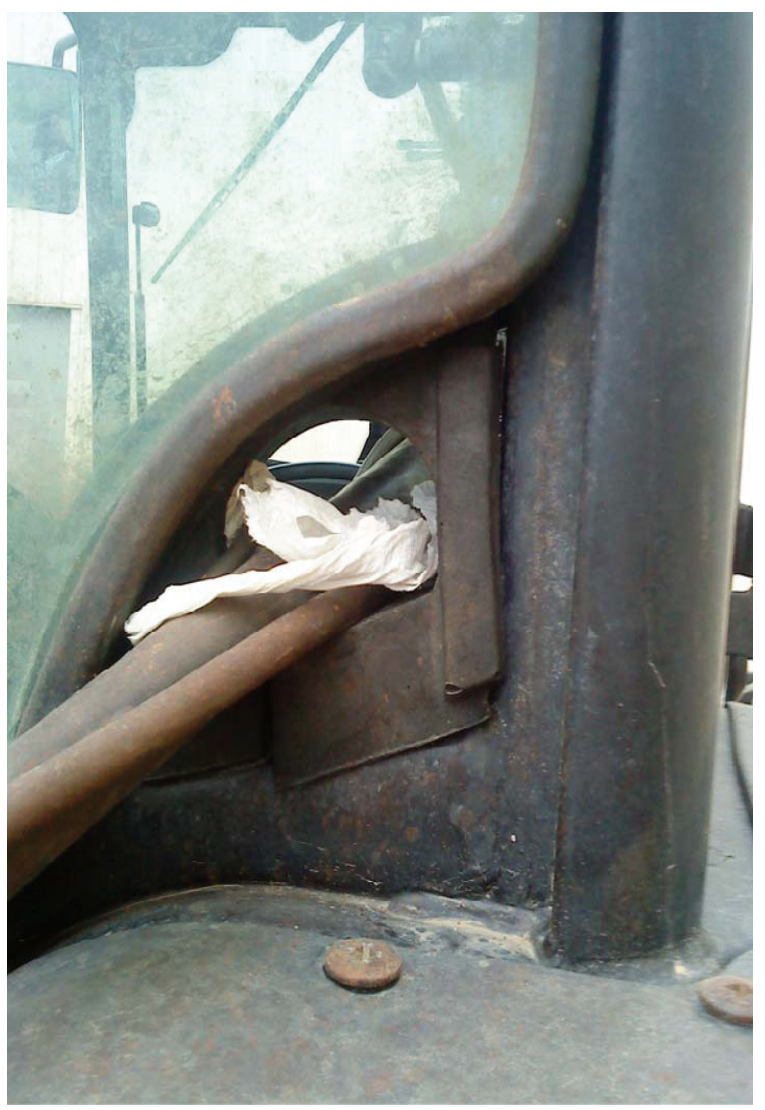

Figure 1: Design flaws on tractor filtering cabs

\subsection{A critical discussion of the effectiveness of Per- sonal Protective Equipment}

Our recent research (Garrigou \& al., [4]) have shown that the type 4 suits which were recommended until recently by prevention institutions were only partially effective.

Furthermore, although this is the class of coverall recommended by the prevention management institutions (Ministry of Agriculture and CCMSA, $\left[{ }^{10}\right]$ ), it is clear that the tests on resistance to permeation by liquids for these coveralls are not conducted using active substances featured in pesticides but with various sulphuric acid and sodium hydroxide-based solutions.

We must also remind that the effectiveness of a suit to pesticide permeation and penetration depends on the particular relationship between the material it is made of and the active substances of the pesticides. Believing that there is on the market a generic suit that would protect against all pesticides is an illusion.

Under normal use and reuse conditions of suits over a long period of time, we can understand that the active substances in pesticides can migrate through the fabric of the suit, hence accumulating and contaminating the farm workers. This may explain the surprising results of the Pestexpo study (Baldi [9]). Indeed a measurement of skin contamination made with gauze patches revealed that suit wearing workers were on the whole more contaminated than workers who did not wear PPE. These results wreaked havoc among the health and safety community.

Besides, the use of PPE also implies significant physiological constraints. D'autre part, le port des combinaisons va se traduire par des contraintes physiologiques importantes. For example in the course of a project carried out in Guadeloupe (French West Indies) in a banana plantation, the worker was wearing a type 4 suit with hood and mask with a $35^{\circ} \mathrm{C}$ temperature and an $80 \%$ relative humidity (see Figure 2 below). We were able to identify that in this pesticide treatment phase that lasted $3 \mathrm{~h} 07$, in a semimountainous environment, the heart beat corresponded to that of a strenuous effort for $2 \mathrm{~h} 20$, an average exertion for $45 \mathrm{~min}$ and a low exertion for 5 min (Balagne $\left[{ }^{11}\right]$ ).

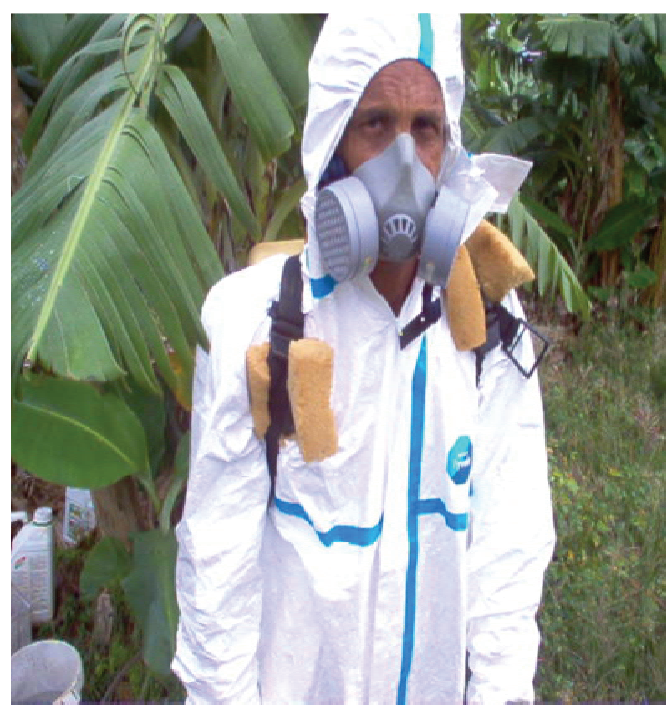

Figure 2: Thermal strain and comfort

The work strenuousness is a reality experienced by workers and it can lead them to compromise pro- 
tection so as to limit the physical demand, especially in terms of thermal comfort. In the course of another study in vineyards, workers stated that they were "too hot in the sun". It must also be noted that the risks and the effects of pesticides are not always perceptible. A vineyard worker explained, "you don't feel anything on your skin, but you can feel it in your airways". This perception - or lack of it can lead vineyard workers to take precautions and wear RPE but not suits or coveralls when it is in fact skin contact that is the most commonly observed route of entry.

It must also be considered that PPE cannot only be approached from a technical standpoint (are they right for the substance?). PPE involve subjective and social dimensions. Indeed, they are perceived as a symbol of prevention, which in itself conveys different representations for different stakeholders. Workers explain that local people sometimes see them as "astronauts", or that using PPE gives a negative image of wine growing, as if the "vineyards and the wine were contaminated by harmful substances" or in the words of another worker "the public sees us and thinks that we are polluters." Several interviewees said that they no longer wore PPE as they had been stopped from doing so by local residents. As they were wearing a suit, they were polluters.

\subsection{Limitations of training programmes}

Training has long been a favoured action in terms of pesticide risk prevention. An analysis of the common training practices showed the following: For many years training programmes focusing on the prevention of risks associated to the use of pesticides were classroom based, with slideshow presentations. The slides presented the toxicological characteristics of pesticides and how they could damage the health. Prevention approaches have also long been centred on the wearing of PPE.

Those training programmes have not bridged the gap between the recommendations they made and what was really (and realistically) put in place day after day in the field. By focusing mostly on the use of PPE (which we now know does not guarantee effective protection) control measures focusing on the equipment technical design and work organisation have long been neglected.

Finally, from a didactic perspective, the programmes relied on the representation that winegrowers were a prevention target to be reached by training programmes. Innovations have recently developed to make winegrowers more active in the prevention process.

\section{What can be learned from an analysis of the activity}

The analysis of winegrower activity, and more precisely the situations of pesticide use, has highlighted the fact that the need for protection has become a complex activity in itself. This selfprotection activity and the prevention of delayed health risks are not fully a part of the wider activity system made up of tending to the vineyard, the production of large quantities of quality grapes, or wine-making.

It generally does not take long for winegrowers to realise that simplistic prevention measures soon become inapplicable in real situations. For example, how to treat a vineyard with a closed cab equipped with a filtration system when the outside temperature is $25^{\circ} \mathrm{C}$ as the temperature inside the cab will be $35^{\circ} \mathrm{C}$ ? Workers will be led to open the side windows to lower the temperature. Another example; after several treatments, the windows are covered with pesticide spray that compromises visibility. Then again, worker will open the windows to manoeuvre more easily. Pesticides can then penetrate the cab.

Regarding the use of protective suits, we can remark that the worker in picture 2 has placed sponges underneath the straps that hold the sprayer so as to protect his shoulders which were hurt by straps and frictions. This reveals a significant contradiction: the worker is wearing a suit as was ordered by his supervisor (he also bears the physiologic cost in terms of thermal comfort) but his needs for adapted equipment (padded straps) are not taken into account.

This poses the problem of risk awareness initiatives and training programmes when they are not accompanied with effective changes to technical systems or work organisation. How can operators be asked to work in full awareness of the risks while they cannot get effective protection? If the protective equipment (whether collective or personal) are only partially effective, workers can believe they are safe when they are not, which, in our view, is the worst possible situation.

This can generate psychological defence and risk denial mechanisms. It then becomes all the more important to stop considering the vineyard worker as a mere receiver of the safety message and involve him or her as an active stakeholder of their own 
health and safety.

Empowering the vineyard worker so as to make him an active stakeholder on prevention issues raises the question of vocational training: acquiring the necessary knowledge and skills to produce in quantity and quality, but also to take health and safety into consideration and use effective protection against risks. That question of knowledge and know-hows cannot be approached without discussing the historic and unequal relationship between farmers and agricultural advisors. For many years, farmers have been able to boost their productivity through the guidance of a wealth of advisors (local Chambers of Agriculture, cooperatives, Department of Agriculture, Trade Unions, pesticide, fertiliser and machine manufacturers, MSA, the French agriculture social security provider), (Cerf \& Maxime $\left.\left[{ }^{12}\right]\right)$.

All those experts and advisors, who supported different and sometimes contradictory agendas and visions and the growingly complex regulatory demands may have contributed to shattering the skills and know-hows until then mastered by farmers or a few experienced people. We then make the hypothesis that farming activity is under the influence of these advisors. They can be seen as the cogs of the above-mentioned technology transfer.

\section{Conclusions}

In this paper we have tried to show that the use of pesticides in France could be seen as a badly controlled technology transfer. This is true in many respects.

- Limitations of the toxicological models used in the marketing authorisation process.

- Limitations of the equipment design processes in general and more precisely the non taking into account of pesticide contamina-

Tibe.shortcomings of protective suits in terms of permeation of pesticides, which explains their ineffectiveness depending on the active substance. These limitations are increased by the fact that the conditions of real use are very different from what may have been defined and characterised in the pesticide manufacturers' laboratories. We then say that using pesticides in agriculture is a complex process of technology transfer, as it was developed by Wisner [1].
Regarding prevention, it is also an object of technology transfer. The protective equipment was initially developed for the industry, the collective protection systems and equipments have not been properly designed, as is the case for mixture and preparation manuals. They are ill adapted to real conditions of use as well as to the particular culture of farm work (in the historic and anthropological sense). Cultural and anthropological dimensions have been little considered in the design stages, whether for work situations or situations of use.

\section{Perspectives}

We have identified different priorities:

- First, it is important to include the modelling of real situations of use in the toxicological models used in the marketing authorisation process.

- Second, taking into account the real situations of use in the agricultural machinery design processes; most importantly for cabs and sprayers.

- Third, the development of training processes that would empower farmers to become active in prevention. Practical workshops and role plays.

Such technical or organisational solutions will only be effective if they are accompanied by a development of skills and room for manoeuvre among farmers. Such technology transfers require different worlds to learn from each other (apprentissages des modes Geslin $\left.{ }^{13}\right]$ and the creation of common worlds (Béguin $\left[{ }^{14}\right]$ ) if they are to be effective and allow a control of the risks they create. In the present French context, the conditions for such learning processes to occur are simply not there. What is at stake is developing the stakeholders' power to act (Clot $\left.\left[{ }^{15}\right]\right)$. This happening is all the more important as workers can belong to groups or loosely structured professional associations such as farm workers or SME employees. The objective is to discuss daily practices from activity analyses. This highlights the diversity of operations and procedures as well as the complex compromises made in the course of work. Organising this discussion starts a process that can favour skill transmission and development. It could also identify risk situations that could then be communicated to prevention institutions and machinery and pesticide manufacturers. 
The difficulties that we observed in France lead us to question what is happening in developing countries (O’Neill $\left[{ }^{16}\right]$ ). Les difficultés rencontrées dans la maîtrise d'un tel transfert de technolgy en France nous interroge sur ce qui peut se passer dans des pays en développement industriel.We shall then develop those elements in the larger perspective of the worldwide evolution of agriculture. Indeed, the evolution of the world's population on the one hand and the recent crises that have impacted food production on the other, have led countries such as China, India or Brazil to invest massively in agriculture. The production models that are implemented are those of intensive agriculture, relying on a heavy use of fertilizers and pesticides. This trend is accompanied by mass investment in agriculture as well as large purchase of lands in Africa. From the lack of control of the technology transfer observed in the French agriculture we could point out the potential consequences of change in global agriculture on farmer and human health.

\section{References}

$\left.{ }^{1}\right]$ A. Wisner, Ergotoxicologie dans les pays tropicaux. In A. Wisner Anthropotechnologie, vers un monde industriel pluri centrique, $1997,1^{\mathrm{e}}$ édition, p. 179-189. Toulouse, Octarès.

$\left.{ }^{2}\right]$ L. Sznelwar, Analyse ergonomique de l'exposition de travailleurs agricoles aux pesticides: Essai ergotoxicologique. Thèse de doctorat en ergonomie, 1992. Laboratoire d'ergonomie du CNAM, Paris.

$\left.{ }^{3}\right]$ B. Mohammed-Brahim, Concept and methods in ergotoxicology. In W. Karwowski (Ed.), International Encyclopedia of Ergonomics and Human Factors, 2000. Taylor \& Francis, London, UK.

$\left[{ }^{4}\right]$ A. Garrigou, I. Baldi, P. Le Frious, R. Anselm, M. Vallier, Ergonomics contribution to chemical risks prevention: An ergotoxicological investigation of the effectiveness of coverall against plant pest risk in viticulture. Applied Ergonomics, Volume 42, Issue 2, January 2011, Pages 321-330.

$\left.{ }^{5}\right]$ M. R. C. Silva, A. A. Clemente, L. F. M. Da Silveira, L. A. Meireles, M. De Simoni, R. M. Carvalho, V. L. M. Veira, Otimizaçao ergonomonica nos tratos cultarais na lavoura de cana de açucar, 1980. Fundaçao Getulio Vargas, Instituto de seleçao e orientaçao profissional, Centro Brasileiro de Ergonomia e Cibernitica, Rio de Janeiro.

$\left.{ }^{6}{ }^{6}\right]$ M., Veiga, F. Duarte, L. A. Meirelles, A. Garrigou, I. Baldi, A Contaminação por Agrotóxicos e os Equipamentos de Proteção Individual (EPIs), 2007. Revista Brasileira de Saúde Ocupacional., volume temático: Exposição a agentes químicos e a Saúde do Trabalhador. 32 (116): 57-68.

[7] M. Veiga Motta, D. Marcondès Silva, D. Bechara Elabras Veiga, \& M. Velho de Castro Faria, Analise da contaminaçao dos sistemas hidricos por agrotoxicos numa pequena comunidade rural do Sudeste do Brasil. 2006, Cad. SaudePublica, 22(11), 2391-2399, nov. 2006. Rio de Janeiro.

$\left.{ }^{8}\right]$ F. G. Palis, R. J. Flor, H. Warburton, \& M. Hossain, Our farmers at risks: behaviour and belief system in pesticide safety. 2006, Advance Access Publication, Vol. 28, n¹, pp. 43-48.

$\left.{ }^{9}\right]$ I. Baldi, P. Lebailly, M. Barrau, V. Bouchart, Y. Lecluse, A. Garrigou, Pesticides exposure in farmers: contamination during treatment days in wine-growing and open field in France (PESTEXPO Study). 2007, Occupational and Environmental Medicine, 64, 43.

$\left[{ }^{10}\right]$ Ministère de l'agriculture et CCMSA, 2007, Traitements phytosanitaires et protection des yeux, du corps, des mains et des pieds.

[11] N. Balagne, Evaluation de l'efficacité de différents EPI dans l'agriculture tropicale. Mémoire de DUT HSE. Bordeaux, Dpt. HSE, IUT, université Bordeaux1.

$\left.{ }^{12}\right]$ M. Cerf, F. Maxime, La coproduction du conseil : un apprentissage difficile. 2006 In J. Rémy, H. Brives, \& B. Lémery (Eds.), Conseiller en agriculture (pp. 137-152). Dijon : Educagri Editions.

$\left.{ }^{13}\right]$ P. Geslin, The development of anthropotechnology in the social and human sciences : its applications on fieldworks ", in P. Carayon and al. (ed.), Human Factors in Organizational Design and Managment - VIII, Santa Monica, IEA Press, pp. 455-460.

$\left[{ }^{14}\right]$ P. Béguin, When users and designers meet each other in the design process. In C. Owen \& P., Béguin (Eds.) Risky Work environments, reappraising human work within fallible systems, 2008, pp. 153-172.

$\left.{ }^{15}\right]$ Y. Clot, 'Clinic of Activity: The Dialogue as Instrument', in Sannino, A., Daniels, H. and Gutierrez, K. (eds.), Learning and Expandingwith Activity Theory 2009, pp. 286-302 (New York: Cambridge University Press).

$\left.{ }^{16}\right]$ D. H. O'Neill, Ergonomics in industrially developping countries: does its application differ from that in industrially advanced countries? 2000, Applied Ergonomics, volume 31, Issue 6 , pages 631-640. 